\title{
How skateboarding made it to the Olympics: an institutional perspective
}

\author{
Dr Mikhail Batuev, \\ Northumbria University \\ mikhail.batuev@northumbria.ac.uk \\ Health and Life Sciences, Northumberland Building, \\ Newcastle upon Tyne, NE1 8ST, UK. \\ +44 (0) 1912273840
}

\author{
Professor Leigh Robinson, \\ University of Stirling \\ leigh.robinson@stir.ac.uk \\ Faculty of Health Sciences and Sport \\ Pathfoot Building, Stirling, FK9 4LA, UK \\ +44 (0) 1786466281
}

\begin{abstract}
Utilizing new institutionalism and resource-dependency theory this paper examines the organisational context within which skateboarding has developed and is continuing to develop. As a radical lifestyle activity, many within the sport of skateboarding have sought to distance themselves from the institutionalized competitive structure exemplified by the modern Olympic Games, despite a steady growth in competitive skateboarding within increasingly formal structures. The aim of this paper is to explore how the sport has operationally evolved and how, as a major youth sport, Olympic inclusion has impacted on its organisational arrangements. Data were collected through a series of semi-structured interviews and supplemented by selected secondary sources including social media analysis, sport regulations and policy statements. The conclusions of the research are: 1) unlike many other sports, skateboarding has always functioned as a network which includes event organizers, media companies, and equipment producers, with governing bodies playing a more peripheral role; 2 ) there was a strong lobby from elite skateboarders in support of inclusion in the Olympics although only on 'skateboarders terms'; 3) interest from the International Olympic Committee (IOC), which eventually led to the inclusion of skateboarding in the 2020 Olympic Games, has affected the organisational evolution of skateboarding over the last decade and has stressed issues of organisational legitimacy in this sport.
\end{abstract}

\section{Keywords}

competitive skateboarding; organisational evolution; Olympic Games; new institutionalism; youth sport; Tokyo 2020 skateboarding commission

Accepted for publication in International Journal of Sport Management and Marketing published by Inderscience.

\section{Introduction}

Skateboarding originated from an activity of skating city streets and objects with 4-wheeled boards. However, the early 1980s marked the arrival of the first professional skateboarding athletes who were able to make a living from the sport, thanks to commercial interest of the sponsors and competitive skateboarding. Competitive skateboarding comprising the disciplines of Vert, Park, Street, Big Air, and Bowl, is considered as a professional sport in this paper, but is only a part of wider phenomenon, which has existed for the last three decades and is encapsulated in the activity of skateboarding. In terms of the organisation of sport, skateboarding is a challenging terrain to research as the sport has never had clear boundaries, which most professional sports have. This is because the culture of the skateboarding 
community has always been based on opposition towards mainstream sport, competitive values and corporate bureaucracy as illustrated below:

Skateboarding, traditionally speaking ... has always been "anti" all of this ... Anti money. Anti corporation. Anti organisation. Anti representation. Anti judgment. Anti hero. Anti team mentality. Anti segregation... You don't skate to get roped into the reality of mass marketing, conspicuous consumption, and the rest of the bullsh*t that constitutes the reality of everyday life. You skate to escape the realities of everyday life. That's why we do it. Everyday life isn't particularly "fun". Skateboarding is.

Bud Stratford (no date), editor of Everything Skateboarding magazine The majority of professional skateboarding athletes accept the idea that they are not just athletes "who happen to ride skateboards, but are 'skaters,' expected to participate in a lifestyle associated with involvement in the sport" (Honea, 2013, p.1255). Until the middle of the 1990s, competitive skateboarding and its commercialization were associated with corporate and bureaucratic behaviour by most skateboarding participants. For instance, this is how skateboarders' attitude to competition during the series of contests in 1991 was reported:

Most of those attending the contests were not actually competing but rather participating in the peripheral activities of watching, fraternizing, and skating apart from the contest. These skaters used the contests to meet new people, learn new tricks, and skate on new and challenging courses... This negotiation between a corporate form of skateboarding and the interests of the skaters is reflected in the registration process... Many of the skaters pinned their numbers so they were difficult to read (e.g., upside down, or at the very bottom of the shirt). This intentional rejection of conformity demonstrates that these skaters were not fully dedicated to the values of the mainstream sport.

Beal $(1995$, p.259-260)

These anti-establishment values are considered fundamental to skateboarding, so there has traditionally been a lack of commitment to competitive skateboarding among athletes and a corresponding resistance to organisational processes.

However, since the middle of the 1990s, with the advent of the ESPN X-Games, the biggest international extreme sport event, and the arrival of Tony Hawk, skateboarding athlete and role model for competitive skateboarding, the sport has become a desirable career option for many athletes. As highlighted by Beal (2013), with the advent of the X-Games, skateboarding has been promoted, not only by its traditional media such as skateboarding magazines and movies, but by mass media, which has played a significant role in establishing the widespread appeal of skateboarding and has been a fundamental driver in its further commercialization and institutionalization. These developments were mainly due to the global television broadcast of the X-Games and the widespread availability of internet video and broadcasting services, such as YouTube, that occurred in the 2000s. 
The most significant change impacting on skateboarding in recent years, has been its inclusion as an Olympic sport in 2016. The Olympic Agenda 2020, the strategic direction for the Olympic Movement, empowered local organizing committees to be able to propose new sports for the Olympic programme. Consequently, the proposal of the Tokyo 2020 Organizing Committee to include skateboarding was approved in August 2016 and skateboarding will make its full Olympic debut in 2020. Skateboarding was previously part of the programme of the 2014 Nanjing Youth Olympic Games (YOG) demonstrating the potential of the YOG to provide an opportunity for the IOC to experiment with new sports and formats which might lead to inclusion in the summer or winter Olympic Games. The inclusion on the full Olympic programme led to the creation of the Tokyo 2020 Skateboarding Commission (TSC), which in turn created a new partnership between the International Federation of Roller Sports (FIRS) and the International Skateboarding Federation (ISF) under the guidance of the IOC. The FIRS will take the lead on "institutional matters", including anti-doping, while the ISF will uphold "freedom of self-expression, passion and creativity" (TSC, 2016). The interest of the IOC in skateboarding and the eventual inclusion of the sport in the Olympics triggered a series of structural changes in the organisation of international skateboarding, which are discussed in more detail below. Thus, the aim of this paper is to explore how the sport has evolved organisationally and how the recent Olympic inclusion has affected its organisational arrangements.

The paper begins with an overview of the appropriate literature, followed by a description of the case based method followed, operationalized by interviews, primarily with elite skateboarding athletes, and document analysis. The results are presented and explained through the lens of new institutionalism and resource-dependence theory - the theoretical perspectives considered appropriate for this research. Finally, conclusions are offered as to the importance of cultural legitimacy in organisational change affecting youth sport. In doing so, one of the major contributions of this paper to the field of knowledge is a thorough explanation of the organisational evolution that skateboarding has gone through, as it has responded to external and internal pressures. It intends to provide a broader understanding of the structural and cultural features of the organisational field of international skateboarding and to analyse the rationales and mechanisms behind changes in it. Finally, it points to the influence that the IOC has on the structural arrangements of sport.

\section{Theoretical background}

Two theoretical perspectives were found to be particularly relevant to the context of this study: new institutionalism and resource-dependence theory. The choice of new institutionalism as the primary theoretical framework for this research was based on the applicability of its major ideas to the research context and a review of empirical studies examining the organisational fields of sports. New institutionalism considers organisations from a sociological perspective and argues that they change in order to conform to expectations in a surrounding field (DiMaggio and Powell, 1983). Specifically, the notion of an organisational field and its dominant institutional logics is relevant to the 
organisation of international skateboarding, which is known for distinctive cultural features, such as creativity, selfexpression and opposition to control. An organisational field is a community where "participants interact more frequently and fatefully with one another than actors outside of the field" (Scott 2001, p. 84) so institutional ideas circulate across organisational boundaries (Sahlin and Wedlin, 2008). Prahalad and Bettis (1986) assert that the organisational field's dominant logic is, in fact, a manifestation of organisational culture at the macro-level because it represents shared ideas and beliefs that guide the behaviour of decision makers in an organisational field. Therefore, as accepted by O'Brien and Slack (2003), the term "dominant institutional logic in an organisational field" is an equivalent of the term "macroculture".

Sport culture can be defined as "a set of core values, beliefs, and attitudes that are common to sport, which set the standards for acceptable behaviours within the sport industry" (Hoye, Nicholson and Smith, 2008, p.507). For the purposes of this paper, culture, in the macro perspective, will be seen through the discussion of the values of skateboarding. While it is understood that culture is more than values and important features may be reflected in other dimensions, such as acceptable ways of working and norms, values have been largely used in literature to examine cultures. Most notably, Smith and Shilbury (2004, p.151), who investigated the culture of Australian sport organisations, concluded that "of the 12 axial codes, which have become the dimensions of organisational culture derived from the data, the most prominent was named 'Values'". Therefore, this study adopts a values-based approach for an approximation of the macroculture of skateboarding.

Donnelly (1996) argues that there is a single dominant sport culture, termed "prolympism", which became established throughout the twentieth century and was created as an articulation of Olympism and professionalism. The growing dominance of this prolympism culture has been evident in the increasing televisualization and commercialization of sport and the difficulties experienced by indigenous and alternative sport ideologies (Donnelly, 1996). Apart from an understanding of what the dominant culture of modern sport is, from a theoretical perspective there was a need to use the concept of subcultures to apply institutional theory to the context of this study. According to Donnelly (2007, p.369370), subcultures are "cultural units sharing much in common with the larger parent cultures, but also possessing identifiable cultural elements of their own". The subculture built around skateboarding activity is one of the distinguishing characteristics of skateboarding as a sport and Tomlinson, Ravenscroft, Wheaton and Gilchrist (2005) have noted that skateboarding is a lived culture that is fundamentally about "doing it"- about taking part.

Linking the notions of culture and subcultures to the organisational field, it is reasonable to follow the approach of Danisman, Hinings and Slack (2006) who discussed the culture of an organisational field from differentiation and integration perspectives, and applied these perspectives to sport. Underpinned by the integration view of the culture of the organisational field that advocates that culture in an organisational field is monolithic and homogeneous, the concept of organisational isomorphism emphasizes "the constraining process that forces one unit in a population to 
resemble other units that face the same set of environmental conditions" (DiMaggio and Powell, 1983, p. 147). Evidence of the phenomenon of organisational isomorphism has been identified in studies of sport organisational fields. For example, studies of the structural evolution of the organisation of sports (Greenwood and Hinings, 1988; Slack and Hinings, 1992; Skinner, Stewart and Edwards, 1999; Hoye et al, 2008) show how isomorphic processes force organisational change from simple structures towards more professional and bureaucratic ones. However, an alternative perspective, that of institutional pluralism, contests the notion of organisational isomorphism. This concept is underpinned by the differentiation view of the culture of an organisational field, which suggests that organisations can fulfil multiple purposes and embody multiple logics (Kraatz and Block, 2008). The possibility of the co-existence of various institutional logics has emerged as a result of studies in sports by Fahlen (2006), Southall, Nagel, Amis and Southall (2008), Southall and Nagel (2008), and Steen-Johnsen (2008), Skirstad and Chelladurai (2011).

Another central concept within new institutionalism is the concept of organisational legitimacy. Summarizing the work of DiMaggio and Powell (1983), Greenwood (2008, p.100) sees new institutionalism as largely "identified with an emphasis on legitimacy rather than efficiency as an explanation for the success and survival of organisations." The notion of legitimacy in new institutional theory was briefly introduced by Zucker (1977) and further developed by Meyer and Rowan (1977). Subsequently, Meyer and Scott (1983, p.201) suggested a definition of organisational legitimacy as ... the degree of cultural support for an organisation-the extent to which the array of established cultural accounts provides explanations for its existence, functioning, and jurisdiction, and lack or deny alternatives .... In such $a[n]$ instance, legitimacy mainly refers to the adequacy of an organisation as theory. A completely legitimate organisation would be one about which no question could be raised. [Every goal, mean, resource, and control system is necessary, specified, complete, and without alternative.] Perfect legitimation is perfect theory, complete (i.e., without uncertainty) and confronted by no alternatives.

It can be seen that organisational legitimacy is directly connected to the culture of the organisational field as it is measured against values, and beliefs. To be precise, this type of legitimacy should be referred as cultural legitimacy in order to differentiate it from regulatory legitimacy. Therefore, cultural legitimacy is "a generalized perception or assumption that the actions of an entity are desirable, proper, or appropriate within some socially constructed system of norms, values, beliefs, and definitions" (Suchman, 1995, p. 574). In contrast, regulatory legitimacy originates not from institutional logics, or culture, but from "rulemaking and enforcement activities within the agencies of the State" (Deephouse and Suchman, 2008, p.56) or cross-national governing organisations. Examples of regulatory legitimation in sport include national sport federations, which are empowered by a state to develop their sports and also authorized by National Olympic Committees to run qualifications for the Olympic Games.

While the sources of regulatory legitimacy are relatively easy to identify, as they are normally state authorities and governing organisations that define rules and regulations in organisational fields, the sources of cultural legitimacy are 
of more abstract construction. As highlighted by Greenwood (2008), based on Giddens (1984) and Seo and Creed (2002), institutional logics are sources of cultural legitimacy, so the central issue of the concept of legitimacy is to determine who has collective authority over cultural legitimation in a specific setting. This question has been discussed extensively in the literature (for example, Meyer and Scott; 1983, Ruef and Scott, 1998) with communities, popular opinion, industry analysts, political activists, and society-at-large being suggested as a source of legitimacy, particularly over long periods of time. However, there has been little application of the concept of organisational legitimacy to the institutional fields of sport, thus there is a potential for it to be used in studies of organisational change in sports.

The literature also establishes the relevance of resource-dependence and power relationships to studies of organisational evolution of international sport. According to resource-dependence theory (Pfeffer and Salancik, 1978), organisations are often unable to generate enough resources for survival, thus they depend on their environment for resources, specifically on resource allocation by other organisations, and therefore change according to the environmental pressures. Resource-dependence thinking underpins the notion of organisational fields as organisations depend on funding from other institutions and change according to the environmental pressures brought about by this. Such interdependencies create the power relationships between legally independent organisations.

Power, inherent to the theory of resource-dependence can be seen from two perspectives. First, as domination or "power over" or second, as a capacity to act / agency or "power to" (Gohler, 2009; Haugaard, 2010). Haugaard (2010) generalizes that the dominative view of power corresponds to political power, while the agency view entails consensual, more democratic forms of power. In this connection, the notion of power links resource-dependence theory with new institutionalism, as coercive isomorphism stems from political influence in that "the more powerful organizations legitimate certain organizational structures and impose coercive pressures on network peers to conform" (O'Brien and Slack, 2004, p.16). There are also pressures by "cultural expectations in the society within which organizations function" (DiMaggio and Powell 1983, p.150).

Thus, the organisational evolution of skateboarding will be analysed within the theoretical framework of new institutionalism with a focus on the concept of cultural legitimacy, supplemented by the concept of resource dependence thinking.

\section{Method}


This paper is based on a case study of the organisational evolution of international competitive skateboarding and is a part of a wider doctoral research project conducted from 2011 to 2016. One of the main advantages of case study methodology, which is necessary to describe and explain a phenomenon, is that it allows the incorporation of multiple research instruments within the case rather than over a sample (Bryman, 1989) and Yin $(2003$, p.8) highlights the case study's unique "ability to deal with a full variety of evidence-documents, artifacts, interviews, and observations." In terms of the specific context of this research, the interpretivist perspective was most suitable as the theoretical perspective for this study as it was necessary to retain the epistemological position of social constructionism and the subjectivist ontological assumptions. These perspectives suggest that meaning and knowledge about phenomena are created by participants and dependent on time, cultural context, and their background. The phenomenological research methodology was believed to allow insight into the topic to be developed and to seek interpretations rather than testing any hypotheses (Creswell, 2013). With the research focus on the organisational evolution of skateboarding, it was found that a processual analysis approach facilitated the achievement of the research objectives as essentially, evolution is a process and needs to be considered as a sequence of events and actions embedded in context and understanding the sequence and flow of events over time. This is a key objective of processual research (Pettigrew, 1997).

With reference to the theoretical framework of this research and consideration of previous contributions, the choice of the unit of analysis was either at the micro level (a specific organisation or territory), or at the macro level (the entire sport). Given the evident lack of academic research into the international organisation of skateboarding, it was considered appropriate to provide a historical documentation of the process of the organisational evolution of this sport. In order to do this, it was decided to consider the whole system of international skateboarding and, consequently, not to limit the research to specific organisations or territories. In other words, the unit of analysis of this study is the international sport of skateboarding. Within international sport no obvious subunits were identified prior to the start of the case study research, and there was an intentional focus on the main unit of analysis, rather than on the smaller subunit level. Thus this study employed holistic case study design.

The research design was operationalized with the use of semi-structured interviews and document analysis. The primary data was collected by interviewing eleven people involved in international competitive skateboarding: current and former professional international skateboarders and officials from the governing organisations (see Appendix for the list of interviewees). Interviews with active international elite athletes was the key source of data. As a brief overview of the context of the study demonstrated, historically athletes have played a key role in the organisation of skateboarding. In addition, individuality and self-expression have always been key features of this sport and it has been centred around individual athletes rather than teams, federations, or specific competitions. Thus, this research assumed athlete 
centrality in skateboarding and prioritized athletes and ex-athletes as interviewees. Athlete rosters for international events were obtained and athletes confirmed to attend were contacted by email, social networks and texts and those who agreed to be interviewed were included in the research. In terms of the officials included in the research, the target was to interview at least one official from the international skateboarding organisations and individuals who held or had held strategic positions in these organisations were approached by email. The face-to-face interviews were carried out at two X-Games events in Barcelona, Spain and in Munich, Germany (May-June 2013) as a number of key informants attended these events.

The analysis also draws on wide range of documents and materials, such as journal articles, discussions in web forums, and post/comments in social networks. In the era of social media, used extensively by skateboarding participants and commentators, analysis of Facebook and Twitter proved extremely helpful to the research as this provided first-hand opinion with no media interpretations. This allowed the corroboration of some interview findings and consideration of the additional perspectives of skateboarding experts, non-professional participants in skateboarding activity, and people interested in skateboarding - the "skateboarding community". Secondary sources of evidence also included documentary analysis of regulations, guidelines and policy statements. All the data was coded and analysed with the use of NVivo software, which served as the main tool of the content theme analysis in this research. One of the main advantages of using NVivo as the content analysis tool was that it was possible to integrate data from various sources and in different formats: from the interviews to social media content (posts, comments, tweets). In NVivo, the system of key words and nodes was developed based on the interview question guidelines This was a useful starting point for data analysis as the assumption is that the more a word is used the greater concerns it reflects (Stemler, 2001). The themes that were identified included the higher order theme Organization of sport, with the associated lower order themes of Institutionalization, Bureaucratization, International governing bodies, National sports organizations, Olympic movement and the higher order theme Culture of sport, with lower order themes being Roots of Activity, Creativity and "Play" and Attitude to mainstream sports. The data was also coded with reference to time periods. The analysis was guided by processual analysis thinking, so, as suggested by Pettigrew (1997), an iterative cycle of deduction and induction was followed.

\section{The history of organisation of international skateboarding}

The professionalization of skateboarding, in the 1980s, was driven both by athletes, who wanted to make a living out of skateboarding, and sponsoring companies that aimed to promote their goods or services. Subsequently, the rise of professional competitive skateboarding and the need for a recognition of it as a sport facilitated the creation of 
governing organisations, or the "Corporate Bureaucracy of Skateboarding" (Beal, 1995). The USA has always been the dominant country in terms of competitive skateboarding development and thus the organisation of skateboarding in the USA has mainly driven the global organisation of the sport. Figure 1 presents the timeline of the major organisational events in international competitive skateboarding.

Figure 1: Timeline of organisation of international competitive skateboarding

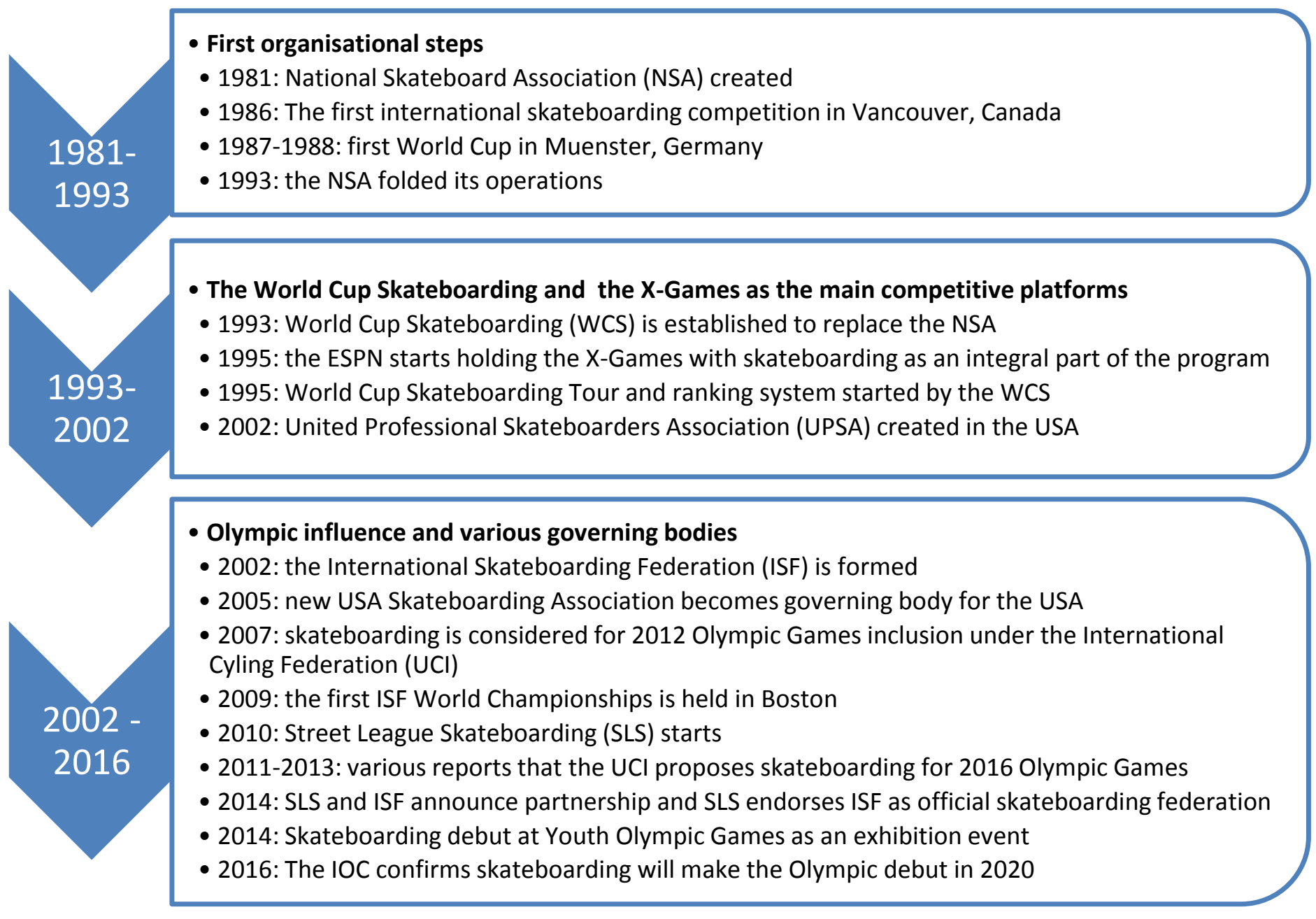

Sources: WCS (2016), ISF (2016), SLS (2016), Beal (2013)

The institutionalization of skateboarding in the X-Games era was visible in the growth of the number of governing skateboarding organisations that were created and/or developed over this period. World Cup Skateboarding (WCS), the global governing body for the sport, was formed in 1993 (WCS, 2016). WCS President Don Bostick summarizes the role of WCS as organizing and establishing "quality skateboarding competitions around the world and offer[ing] a ranking system that honours and gives value to skaters' accomplishments in competitive skateboarding" (Young, 2013, p.40). 
In addition to WCS, other organisations have claimed to be international governing bodies for skateboarding. The World Skateboarding Federation (WSF) was established in 2014 and claims to be "the only international skateboarding organisation to include all disciplines of skateboarding" (WSF, 2016). There is also the aforementioned International Skateboarding Federation (ISF), established in 2002 after "stakeholders in the sport agreed a need to establish a governing body to provide direction and governance" for skateboarding (Cutler, 2011, p.30). Finally, the International Federation of Roller Sports argued that, as roller sports include skateboarding in its various disciplines (Slalom, Downhill, Street, and Vert), skateboarding clearly belongs to roller sports (FIRS, 2016), despite the fact that the FIRS has lacked support from competition organisers, skateboarding athletes and the skateboarding community. However, as highlighted in the introduction and as will be discussed below, the FIRS has a significant role to play in the Olympic future of skateboarding.

\section{Structure of competitive skateboarding}

The skateboarding community has always been fearful of a loss of autonomy and holds a belief that skateboarding must be organized by skateboarders (Thorpe and Wheaton, 2011). As a consequence, international skateboarding has had little organisational structure, rather has functioned as a network of individuals and organisations. There has been an understanding among the officials in charge of competitive skateboarding that the skateboarding community would reject significant changes that copy the organisational practices of mainstream sport. From a structural perspective, as competitive skateboarding has remained very fragmented over the last two decades, a number of international organisations, such the FIRS, the International Cycling Union (UCI), and the ISF, have attempted to establish control over this sport. These attempts have been mostly connected to the interest of the IOC to make the Olympic program more relevant for younger audience, which materialized in the introduction of skateboarding into the Games. Figure 2 presents the map of international governing bodies currently connected to skateboarding (FIRS, ISF, WSF) and the biggest event's organizers (X-Games, World Cup Skateboarding, Street League Skateboarding). 
Figure 2: Organisation of international competitive skateboarding

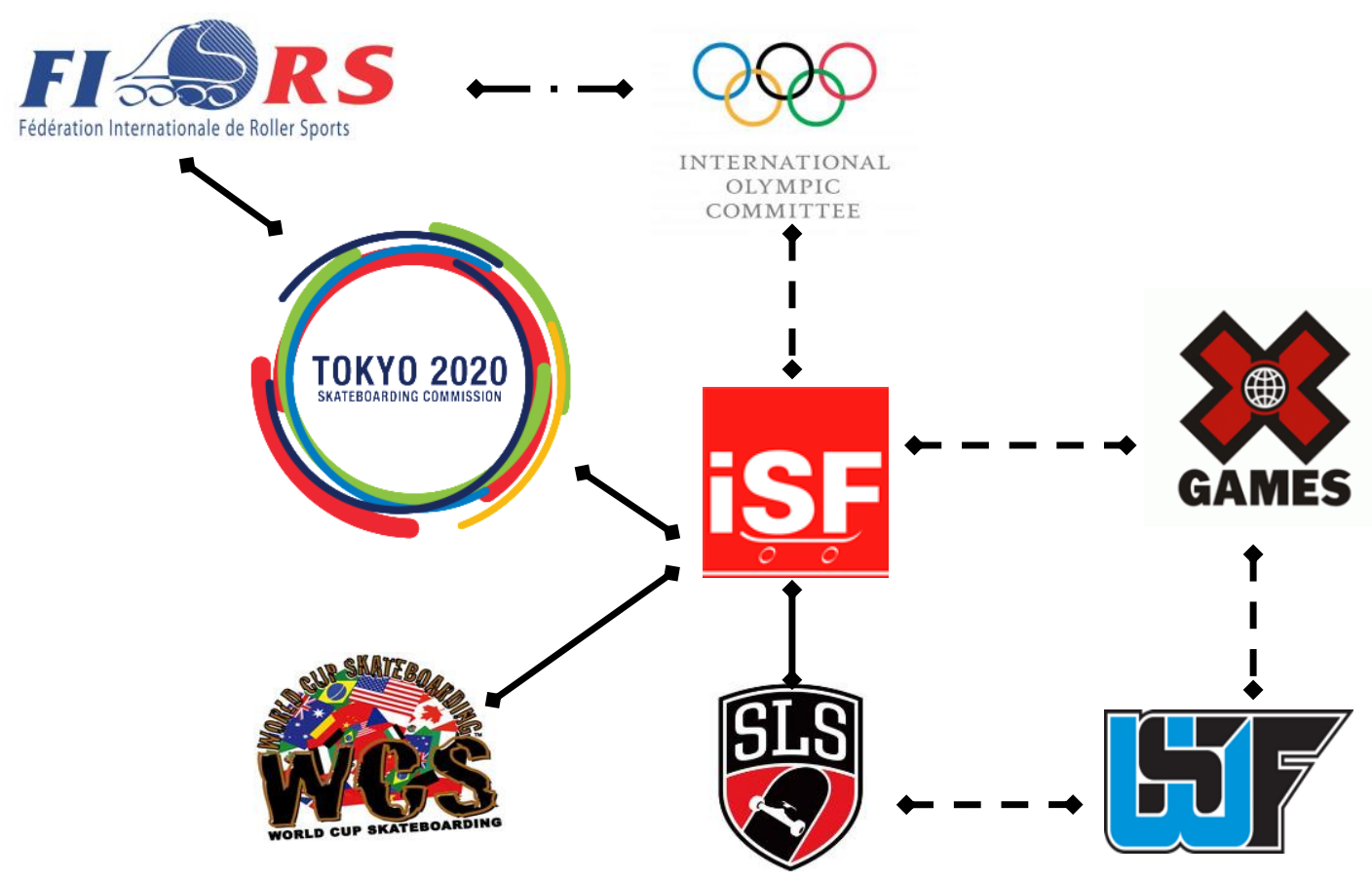

$\leftarrow$ - $\bullet \quad$ Informal relationships

Formal relationships

IOC Recognition

Only the FIRS is recognized by the IOC although the FIRS has never organized or sanctioned any significant international event. This occurred because the IOC considered skateboarding as a roller sport and therefore recognized the FIRS as the international governing body for skateboarding. However, the IOC also recognises the role of the ISF and requires the FIRS to work in partnership with this organisation in the delivery of skateboarding as an Olympic sport through a formal relationship with the Tokyo 2020 Skateboarding Commission.

One of the founders and current president of the ISF, Gary Ream (2013, interviewee) highlights that the ISF was established to protect the skateboarding, to make sure that if it enters the international sport scene, which is the Olympics, it will be represented in a proper way. This reflects the concerns of professional athletes, as noted by Tony Hawk, a professional skateboarder: 
I think the catalyst for the formation of ISF was to have a committee ready if the IOC wanted to put skateboarding in the Olympics .... There are a lot of different hoops you have to jump through and a lot of bureaucracy to become a sanctioned organizer of an event and change how the IOC sees you as a sport. The formation of the ISF was the skateboard industry being proactive and preparing for that Olympic opportunity. There are other established committees and sanctioning groups that can claim jurisdiction over skateboarding and have no agenda for Olympic inclusion. I think it is a good thing that the skateboarding industry was organized enough to protect itself in that respect.

Tony Hawk in Cutler (2011, p.30)

A number of professional skateboarders and representatives of influential commercial skateboarding companies were behind the establishment and functioning of the ISF. However, although the ISF has always been very commercially focused, the interests of skateboarders have also been well represented within the organization of the ISF. Indeed, the notion of a skateboarding governing body emerged from one of the International Association of Skateboarding Companies ${ }^{1}$ open meetings when Gary Ream explained "that if the world of skateboarding doesn't pull together and enter the Olympics on purpose, someone else will eventually succeed in entering it" (Cave, 2014, no page number). The ISF office is based in Woodward Camp Pennsylvania, the action sport business venture of Gary Ream. Therefore, it is evident that the ISF works in an informal "network" way, bringing together skateboarding participants as a governing body, as well as commercial skateboarding companies and other commercial actors.

As can be seen from Figure two, the ISF also has established relationships with the biggest competition organizers in skateboarding-the X Games, the WCS and Street League Skateboarding (SLS). The Street League Skateboarding (SLS) is the competition series founded by professional skateboarder Rob Dyrdek in 2010 to "foster growth, popularity, and acceptance of street skateboarding worldwide" (SLS, 2016, no page number). The SLS competition format and judging system was a completely new experience for international competitive skateboarding and, in organisational terms, serves as a link between the traditional culture of skateboarding creativity and the standardization of competition rules. With the introduction of the SLS competition format, skateboarding athletes began to see how skateboarding might look like in the Olympic Games:

The Street League is the reason why the Olympics would even consider taking it, because this is about as close to the Olympic skateboarding as you might have built it yet. They [the SLS] worked pretty hard to make it structured: everything can be judged only one way. . If they [the IOC] are on a fence thinking about the decision, I'm sure they are watching this [Street League] as a guide of what they might do.

\footnotetext{
${ }^{1}$ The International Association of Skateboarding Companies "is a diverse group of skateboard manufacturers, distributors, contest organizers, private skateparks, and individuals. A collaboration of people passionate about skateboarding- with the single aim of protecting the integrity of skateboarding and pushing skateboarding forward on a global level" (IASC, 2016).
} 
Thus, the SLS is the competition format deliberately introduced as an organisational compromise between traditionally loose competition rules, which reflect skateboarding values, and the need for the standardization of sport regulations. Specifically, in terms of following skateboarding values, the SLS format does not restrict athletes in the tricks they can do. It does, however, favour the technical side of skateboarding rather than its "style" component, as the instant scoring system is focused on the difficulty of tricks and not on style. This compromise fits well with the concept of competitive skateboarding in the Olympic Games.

\section{Cultural considerations}

Over the decades, skateboarding has been viewed by many participants as an alternative lifestyle rather than as a sport in which winning competitions is important (Wheaton, 2004). None of the modern top competition skateboarders, who were interviewed, consider winning competitions as a number one career priority. For example, 38-year-old professional skateboarder from Brazil, Sandro Dias (2013, interviewee), claims that nothing has really changed in his attitude toward skateboarding since he started this activity for fun as a child:

The feeling that I am still having is that skateboarding is for fun. And it is all the same because I love to do this. I am a professional skateboarder not because it is all about the money. I am a professional skater, because I love to skate. I love to skate every day still. I love to skate with my friends. I don't like to practice for a contest, I like to skate! That is the difference.

Likewise, most interviewees expressed their deep and sincere belief in what can be called alternative skateboarding values. Therefore, the research provides evidence to argue that traditional sporting values of competitiveness and winning are not seen as most important by professional athletes, despite the fact they take part in competitions.

It is clear that culturally skateboarding is very different from most mainstream sports and doesn't fit the ideals of the Olympic movement. Indeed, arguably, it would not be an understatement to say that historically there has never been a more "anti-Olympic" sport than skateboarding and most skateboarders do not consider themselves competitors, rather they are the opposite: they are all friends and "homies"2. Consequently, the values of skateboarding do not fit the organisational features that are traditional and obligatory for Olympic sports. For example, the Olympic Games is the event where athletes represent their respective countries. Skateboarding participants claim that skateboarding allows them to express personality, it is about individuality and has little to do with nationalism (X-Games, 2014). Competitive skateboarding has never had a drug testing regime and as organized competitions are quite new to skateboarding, drug

\footnotetext{
${ }^{2}$ Homies - slang term often used in skateboarding communities. It means friends from home town who one usually does skateboarding with.
} 
testing is something unthinkable for many skateboarding participants, something that goes against traditional values of their activity.

Many participants expressed their views strongly against skateboarding in the Olympics in online petitions (Haveboard, 2007; Clark, 2016), and publications (X-Games, 2014, Stratford, no date), suggesting that the alternative cultural values, which skateboarders have always promoted, are "incompatible with the disciplinary, hierarchical, nationalistic Olympic regime" (Thorpe and Wheaton, 2011, p.831). For example, more than 7500 people signed this petition:

With due respect for Olympic Athletes, we the undersigned skateboarders and advocates strongly request that the IOC NOT RECOGNIZE SKATEBOARDING AS AN OLYMPIC SPORT, or use skateboarding to market the Olympics. Further, we ask that the IOC NOT recognize any individuals or groups claiming to be the $\mathrm{IOC}$ recognized governing body of skateboarding or provide funding to them. Skateboarding is not a "sport" and we do not want skateboarding exploited and transformed to fit into the Olympic program. We feel that Olympic involvement will change the face of skateboarding and its individuality and freedoms forever. We feel it would not in any way support skateboarders or skateparks. We do not wish to be part of it and will not support the Olympics if skateboarding is added as an Olympic sport.

Clark (2016, no page number)

Nonetheless, this research indicated that most elite skateboarders are supportive of the idea of Olympic skateboarding in general. A recently retired skateboarder, Rob Dyrdek (2013, interviewee), suggested in his interview that skateboarding should be in the Olympics and that it would be incredible for a skateboarder to win the gold for his country. Most of those interviewed welcomed the Olympic inclusion but were concerned about the way it would be organized within the Olympic movement. The opinion of Sandro Dias highlights a belief that skateboarding should only enter the Olympics on "skateboarding terms":

I agree to see skateboarding in Olympics, because skateboarding is something, which is worldwide... As far as the Olympics respect our rules, it would be good for us. As far as they respect our love to skateboarding, it would be good for the Olympics. If they try to change something like our rules, format of competition, our lifestyle that would be not good-I don't agree then. I am out then, cause we don't need the Olympics. They need us, because they are too "old." So if they need us, please respect us. But if they keep our format and our rules to fit them into the Olympics, it would be very good for us. And that would be very nice for the market and for the whole industry.

Sandro Dias, professional skateboarder (2013, interviewee)

The major concern is how the Olympic skateboarding should be organized in order to preserve skateboarding values, and have a credible regulation and judging system. Arguably, this concern is addressed by the existence of the Street 
League Skateboarding (SLS) which offers a reasonable compromise between what the IOC wants to see and what the skateboarding community is used to.

\section{Discussion}

New institutional theory has been predominantly concerned with explaining organisational change through "convergent" change that is evident in the similarities or differences among organisational structures and processes in institutional fields (Scott, 2004). Academic discussion of the structures of sport organisations has been mainly situated in the context of organisational change and has addressed the transformation of amateur sport organisations into professional ones. This has led to the formalization and bureaucratization of sport. Most studies of organisational change in sports have suggested that, only in rare cases, have sport organisations (and no international federations) escaped isomorphic trends and demonstrated some variation in structures. For example, Flatum (2013, interviewee) and Steen-Johnsen (2008) referred to the example of the Norwegian Snowboard Federation (the NSBF) that won a battle to attain the status of an autonomous federation responsible for snowboarding in Norway, as the Norwegian Skiing Federation sought to incorporate the sport. Consequently, organization of competitive snowboarding in Norway can be characterized by a "strong degree of interactivity in organizational processes, the informality and the preference for making decisions without the explicit use of authority" (Steen-Johnsen, 2008, p.347).

Thus, in the case of Norwegian snowboarding, the network structure of the national snowboarding organization continued to influence the sport, even though some formal structural criteria had to be fulfilled by the NSBF. The organisational evolution of competitive snowboarding seems to be the most relevant example for the sport of skateboarding due to overlapping communities and similarities of the "board" cultures. Consequently, learning from snowboarding's Olympic history, the skateboarding community has been anxious about an Olympic future for their sport and reluctant to allow skateboarding to be governed by the international federation of another sport.

The IOC has strict criteria regarding the structure of sports, so pressures for bureaucratization associated with Olympic recognition of governing bodies have been strong (Augestad, Bergsgard and Hansen, 2006; Skille, 2011). However, the findings of this research indicated that structural arrangements in international skateboarding have evolved in a significantly different way in comparison to those in mainstream sports. One might have expected that the professionalization and commercialization of the sport would have neglected the cultural features of skateboarding and thus the isomorphic processes, similar to "civilization" in the humanist perspective of culture, thought to establish modern competitive sport (Girginov, 2010, p.400) would have occurred and been reflected in the bureaucratization and 
formalization of the international sport structures. Yet this only happened to a certain degree despite forces entering the organisational field of the sport.

International competitive skateboarding still does not have one leading international organisation responsible for the governance of the whole sport. The research identified that there were several international governing organisations working together in control of specific parts and segments of the sport. Major international skateboarding organisations, such as the ISF, the WCS and the WSF, are structured as networks and consequently, they have been institutionalized to a very limited extent and have remained relatively informal, with little bureaucratisation. In terms of Mintzberg's (1979) organisational theory, networks in youth sports are an organisational "adhocracy" with "the symbiotic relationship between the extreme athletes and spectators, managers of sport broadcasting, and managers of corporate sponsorships for sporting events" (Mawson, 2002, p.257). Therefore, a network - a typical structure in skateboarding, but an unusual organisational design for international sports, was found to have remained strongly present. To summarize, the field of international skateboarding has always been diverse in terms of the structure of this field and the multiple logics that the organisations embody, which are competitive and commercial logics in addition to the traditional "alternative" logics of skateboarding. Thus the notion of institutional pluralism explains the evolution of the field of international skateboarding,

One of the key questions that this research addressed, was how cultural legitimacy in skateboarding corresponds to regulatory legitimacy within the global sport governance frameworks. It is critical for the survival of international skateboarding organisations to establish cultural legitimacy, because regulatory legitimacy has not yet been established. The relationships between these two concepts have been manifested through the attitude of top athletes in these sports towards participation into the Olympic Games. Although it is understood that relationships between cultural and regulatory legitimacies are more complex than simply the athletes' attitudes to the Olympic Games, these views indicate the degree of the lack of cultural legitimacy of the Olympic movement within much of the skateboarding community. Overall, the majority of professional athletes in competitive skateboarding wanted to participate in the Olympics. However, these findings do not mean that the Olympic movement has been culturally accepted by all competitive skateboarders. Athletes indicated their willingness and desire to participate in the Olympics, and almost all of them pointed out that there are tangible benefits of participation in the Olympic Games, both for the athletes' careers and the development of the sport in general. However, for the skateboarding community, the IOC has significantly less cultural legitimacy than other institutions, such as the X-Games. This also applies to the FIRS where, using its debatably legitimate position with regards to skateboarding and its status as the IOC recognized governing body, it has maintained authority over international skateboarding. 
The contrast between cultural legitimacy and regulatory legitimacy, which is mainly associated with the institutional isomorphism of mainstream sport organisations, is central to the understanding of the organisational evolution of skateboarding. As cultural legitimacy reflects a degree of cultural support for organisations, it is also manifested in resistance towards governing organisations. In other words, when the cultural legitimacy of organisation is significantly lower than its regulatory legitimacy, then resistance of sport participants towards this organisation is likely to occur. This study identifies three main issues that contributed to a lack of cultural legitimacy of the governing organisations of skateboarding. These are a) hierarchical mainstream sport organisations entering the institutional field, where network organisation structures have been common; b) cultural gaps between the traditional values of skateboarding and the modern competitive values of modern sport and c) a lack of communication between mainstream governing bodies and skateboarding athletes, organisations and communities.

There has been strong resistance amongst the skateboarding community, but resistance was directed towards the concept of sport governance as a whole, rather than towards specific organisations. Skateboarders have campaigned against the idea of skateboarding joining the Olympic movement and the corresponding requirements of governance of the sport by a single international organisation. This resistance is rooted in the history of skateboarding and is associated with the notion of competition in skateboarding:

Contests are almost new to skateboarding I feel, because skateboarding is just an individual thing... That is always making it more fun rather than thinking about the contests only and about winning. These are not the roots of skateboarding.

Ryan Decenzo, professional skateboarding athlete (2013, interviewee)

The activity was not meant to be competitive and was initially created as an alternative to mainstream sports. Indeed, the very first competitions in skateboarding were held for the fun of the participants. However, a rise in the popularity of competitions and the development of organisational structures around competitions led to the rise competitive aspect of the activity, a shift in values, and a rift of cultural nature.

When considering the inclusion of the sport within the Olympics despite this lack of cultural legitimacy, resourcedependence thinking offers an explanation for some of the decisions and strategies employed by the various international sport federations, including developing relationships with the IOC, creating power/dependence relationships with other sport organisations and attempting to establish control over skateboarding. In this research, one of the most evident examples of resource-dependence organisational behaviour is the establishment and activities of the ISF. The existence of this organisation is related to the IOC's perceived interest in skateboarding, as the ISF was established with the primary objective to "protect skateboarding" and since has been following a strategy aimed at strengthening its control over international skateboarding. As the key pillar of this strategy, the ISF has built mutually 
beneficial relationships with all the key organisations in the institutional field of international skateboarding: the FIRS, the WCS, the US Skateboarding, the SLS, and the X-Games. Backed by people with perceived influence in skateboarding, such as Tony Hawk, the ISF has maintained its autonomy from the IOC and effective power over the international skateboarding network.

International competitive skateboarding has always functioned with a network of commercial actors. As described earlier, the founders and officials of the ISF come from the commercial side of skateboarding. Via its board and its network, the ISF remains connected to the huge market of skateboarding in an informal way, despite being a de-jure non-for-profit organization. In terms of power/dependency relationships, this means that, in order to secure necessary resources for its existence without compromising its autonomy from the IOC, the ISF has to have some resource motivated relationships with the biggest commercial actors in skateboarding, such as board producers, media companies, and skateboarding facilities. Relationships between these commercial organisations and the ISF can be seen as mutually dependent as the ISF depends on funding from commercial entities and also their support in terms of protecting skateboarding values. These businesses depend on the ISF in terms of preferential access to new international markets and major international skateboarding events.

Even facing constraints and uncertainty over the flow of resources from the environment, quite uniquely in terms of resource-dependence theory, the ISF has not sought to gain access to Olympic resources and has maintained the position that skateboarding does not "necessarily need to be in the Games, and that the non-competitive component of skateboarding, with or without the Games, will always be its heart and soul" (Gary Ream in Bane, 2011). Nevertheless, informal communications between the ISF and the IOC developed into a close cooperation between these governing bodies, as the ISF was asked by the IOC to organise a skateboarding showcase event at the 2014 Youth Olympics and later became a part of Tokyo 2020 Skateboarding Commission. However, the ISF has never been officially recognised by the IOC as a sport governing body, arguably because its dependency on commercial organisations. In a reference to the ISF, Ricci Bitti, the president of the Association of Summer Olympic International Federations, suggested that "a proper international body not driven by commercial opportunities must run skateboarding" (Radnedge, 2015, no page number). Overall, in terms of the "power to" and "power over" concept (Gohler, 2009; Haugaard, 2010), using their relationships with the key commercial actors in skateboarding, the ISF has been established itself as the "agency" in the international skateboarding network, but has remained independent from the IOC.

The organisational strategies and behaviour of the IOC can also be viewed from a resource-dependence perspective. Broadly speaking, the IOC call to include more youth sports and, in particular, the interest of the IOC in skateboarding 
can also be seen as resource-motivated behaviour because the IOC wants to improve television ratings and to appeal to youth. However, these dependency relationships have been poorly reflected in the power relationships of skateboarding and the Olympic movement as the international sport governing bodies have little autonomy when dealing with the Olympic movement. Therefore, whilst there is a mutual dependence between the $I O C$ and skateboarding, the power imbalance is evident as the IOC has the ultimate "power over" the sport within this relationship.

\section{Conclusion}

This paper has presented a complex story of the organisational evolution of skateboarding: the sport that over the last twenty years has rapidly developed from a lifestyle activity, which distanced itself from a competitive sport, to one of the most popular new youth sports. It extends previous applications of institutional and resource-dependence theories to a sport that has a unique history and logic behind its organisation. International competitive skateboarding has always functioned as a network, consisting mostly of commercial actors, such as media companies, event organizers, and equipment producers. The role of governing bodies has always been of limited significance in skateboarding organisational structures. This might change with skateboarding entering the Olympic movement, even though there has been no indication from skateboarding athletes and event organizers that international skateboarding needs a single organisation to govern it.

Historically, studies of organisational evolution and change in modern sports tend to focus on professionalization, isomorphic trends, power, and political issues (O'Brien and Slack, 2003; Morrow and Idle, 2008). Whereas all of these aspects can explain the organisational evolution of modern sports, the importance of the concept of cultural legitimacy of international sport organisations emerges from this study. It is apparent from this research that the role of cultural legitimacy of international sport organisations in organisational field has been undervalued in sport management as cultural profiles provide a foundation for structural arrangements and determine whether organisational change is accepted or not. In this connection, the role of athletes in legitimizing structural change and the danger for a culturally legitimate organisation to lose the "ownership" of their sport, due to not being recognized by the IOC, emerges as critical issues for the international organisation of a youth sport. Whereas this paper demonstrates that culturalcognitive elements and subcultures clearly have a strong effect on structural arrangements in skateboarding, there is still a lack of understanding how they work and how they influence changes in modern sport in general. Therefore, there is value in investigating this further in the context of the evolution of very recent sports, for example parkour, or the activities that are not yet recognized as sport, such as electronic sports. 
There are wider implications of this study for sport practitioners in terms of sport management and the organisation of international sports. Whereas it is found that network organisational structures reflect a traditionally informal way to organize skateboarding and are in line with values of this sport, the adherence to these types of structure is thought to restrict the development of the sports. An absence of central authority and overlapping international competition structure with multiple events, tours, and organisations constitute a challenge for sport managers of these sports in terms of delivering their international proposition. In other words, it might be simply not appealing to spectators, sponsors, and media to follow a sport with no clear competition structure. So this study contributes to wider sport management knowledge by raising a question of the sustainability of unconventional organisational setups in the global sport business, even if they are considered the only culturally legitimate structures in this field.

After more than a decade of rumours and discussions, skateboarding is now an Olympic sport. Its inclusion will be an excellent addition to the Olympic programme in Tokyo and will do much to fulfill the ambitions of the Olympic Agenda 2020 and of the Tokyo Games organisers in relation to their declared focus on appealing to youth. However, the skateboarding community has always been concerned that the consequences of Olympic inclusion could be similar to those experienced by the sport of snowboarding following its inclusion in 1998: bureaucratization of the sport and further cultural separation between competitive and non-competitive skateboarding. Thus it has been critical for the community and the athletes that skateboarding is in the Olympic Games on "skateboarding terms". The organisational arrangements currently look like a compromise between the values of the Olympic movement and the skateboarding community, such as the full institutionalization of sport versus retaining a fair degree of anti-establishment flexibility; formality of sport regulations versus creativity of expression in skateboarding; and strict judging criteria versus choosing the personal favourite. Only time will tell how these new organisational arrangements will work and what this new Olympic era will bring to the evolution of skateboarding. 


\section{References:}

Augestad, P., Bergsgard, N. A., Hansen, A.O. (2006) The Institutionalization of an Elite Sport Organisation in Norway-The Case of "Olympiatoppen". Sociology of Sport Journal, 23 (3), pp. 293-313.

Bane, C. (2011) ISF, UCl, and the IOC. Available:

http://sports.espn.go.com/action/skateboarding/news/story?id=6361581 .

Beal, B. (1995) Disqualifying the Official: An Exploration of Social Resistance Through the Subculture of Skateboarding. Sociology of Sport Journal., 12 (3), pp. 252.

Beal, B. (2013) Skateboarding: the ultimate guide. Santa Barbara: ABC-CLIO, LLC.

Brixey, W. (2012) Skateboarding vs. The Olympics: a brief history. Available: http://www.jenkemmag.com/home/2012/09/04/skateboarding-vs-the-olympics-a-brief-history/

Bryman, A. (1989) Research methods and organization studies. London; Boston: Unwin Hyman.

Cave, S. (2014) Skateboarding in the Olympics? Available: http://skateboard.about.com/od/events/a/Olympics.htm

Clark (2016) "No Skateboarding in the Olympics: Online Petition. Available:

http://www.thepetitionsite.com/takeaction/656/763/888/.

Creswell, J. W. (2013) Qualitative inquiry and research design: choosing among five approaches. Los Angeles: SAGE Publications.

Cutler, M. (2011) The X Factor. Sport Business International, 03 (165), pp. 28-29, 30.

Danisman, A., Hinings, C.R. and Slack, T. (2006) Integration and Differentiation in Institutional Values: An Empirical Investigation in the Field of Canadian National Sport Organizations. Canadian Journal of Administrative Sciences, 23 (4), pp. 301-317.

Deephouse, D. and Suchman, M. (2008) Legitimacy in organisational institutionalism. The SAGE Handbook of Organisational Institutionalism, , pp. 49-77.

DiMaggio, P.J. and Powell, W.W. (1983) The Iron Cage Revisited: Institutional Isomorphism and Collective Rationality in Organisational Fields. American Sociological Review, 48 (2), pp. 147-160.

Donnelly, P. (1996) Prolympism: Sport Monoculture as Crisis and Opportunity. Quest, 48 (1), pp. 25-42.

Donnelly, P. (2007) 'Toward a Definition of Sport Subcultures', in A. Tomlinson (ed.) The Sport Studies Reader. London: Routledge

Fahlen, J. (2006) Structures beyond the frameworks of the rink: on organisation in Swedish ice hockey.

FIRS (2016) About FIRS. Available: http://www.rollersports.org/RollerSports/content/about.html

Giddens, A. (1984) The constitution of society: outline of the theory of structuration. Berkeley: University of California Press.

Girginov, V. (2010) Culture and the Study of Sport Management. European Sport Management Quarterly, 10 (4), pp. 397-417. 
Gohler, G. (2009). 'Power to' and 'Power over'. In S. R. Clegg \& M. Haugaard The SAGE handbook of power (pp. 27-39). London: SAGE Publications Ltd

Greenwood, R. and Hinings, C.R. (1988) Organisational Design Types, Tracks and the Dynamics of Strategic Change. Organisation Studies (Walter De Gruyter GmbH \& Co.KG.), 9 (3), pp. 293-316.

Greenwood, R., (2008) The SAGE handbook of organisational institutionalism. Los Angeles; London: SAGE.

Haveboard (2007) No Olympic Skateboarding. Available: http://haveboard.com/no olympic skateboarding/

Haugaard, M. (2010). Democracy, Political Power, and Authority. Social Research, 77(4), 1049-1074.

Hoye, R., Nicholson, M. and Smith, A. (2008) Unique aspects of managing sport organisation. In: C. Wankel, ed. 21st Century Management: A reference handbook. Thousands Oaks, CA: Sage ed. , pp. 499-507.

Honea, J.C. (2013) Beyond the Alternative vs. Mainstream Dichotomy: Olympic BMX and the Future of Action Sports. The Journal of Popular Culture, 46 (6), pp. 1253-1275.

IASC (International Association of Skateboarding Companies) (2016) About: Our Mission. Available: http://theiasc.org/about/

ISF (International Skateboarding Federation) (2016) Mission Statement. Available:

http://www.internationalskateboardingfederation.com/about/mission-of-the-isf

Kraatz, M.S. and Block, E.S. (2008) Organizational implications of institutional pluralism. The Sage Handbook of Organizational Institutionalism, 840, pp. 243-275.

Mawson, L.M. (2002) The eXtreme sport challenge for sport managers. International Journal of Sport Management, 3 (4), pp. 249-261.

Meyer, J.W. and Rowan, B. (1977) Institutionalized Organisations: Formal Structure as Myth and Ceremony. American Journal of Sociology, 83 (2), pp. 340-363.

Meyer, J.W. and Scott, W.R. (1983) Organisational environments: ritual and rationality. Beverly Hills: Sage.

Mintzberg, H. (1979) The structuring of organisations: a synthesis of the research / Henry Mintzberg. Englewood Cliffs; London : Prentice-Hall, 1979.

Morrow, S. and Idle, C. (2008) Understanding Change in Professional Road Cycling. European Sport Management Quarterly, 8 (4), pp. 315-335.

O'Brien, D. and Slack, T. (2003) An Analysis of Change in an Organisational Field: The Professionalization of English Rugby Union. Journal of Sport Management, 17 (4), pp. 417-448.

O'Brien, D. and Slack, T. (2004) The Emergence of a Professional Logic in English Rugby Union: The Role of Isomorphic and Diffusion Processes. Journal of Sport Management, 18 (1), pp. 13-39.

Pettigrew, A.M. (1997) What is a processual analysis? Scandinavian Journal of Management Scandinavian Journal of Management, 13 (4), pp. 337-348.

Pfeffer, J. and Salancik, G.R. (1978) The external control of organisations: a resource dependence perspective. New York: Harper \& Row. 
Prahalad, C. K., and Bettis, R.A. (1986) The dominant logic: A new linkage between diversity and performance. . Strategic Management Journal, 7 (6), pp. 485-501.

Radnedge, (2015) Promoters Cannot Run a Sport, Ricci Bitti Warns Skateboarding. Available: http://aroundtherings.com/site/A 53485/Title Promoters-Cannot-Run-a-Sport-Ricci-Bitti-WarnsSkateboarding/292/Articles

Ruef, M. and Scott, W.R. (1998) A Multidimensional Model of Organisational Legitimacy: Hospital Survival in Changing Institutional Environments. Administrative Science Quarterly, 43 (4), pp. 877-904.

Sahlin, K. and Wedlin, L. (2008) Circulating ideas: imitation, translation and editing. , pp. 218-242.

Scott, W.R. (2001) Institutions and organisations. Thousand Oaks, Calif.: Sage Publications.

Scott W. R. (2004). Institutional theory: Contributing to a theoretical research program. In Smith K. G., Hitt M. A. (Eds.), Great minds in management: The process of theory development (pp. 460-484). Oxford, UK: Oxford University Press

Seo, M. and Creed, W.D. (2002) Institutional contradictions, praxis, and institutional change: A dialectical perspective. Academy of Management Review, 27 (2), pp. 222-247.

Skille, E. (2011) Change and isomorphism-A case study of translation processes in a Norwegian sport club. Sport Management Review, 14, pp. 79-88.

Slack, T. and Hinings, B. (1992) Understanding Change in National Sport Organisations: An Integration of Theoretical Perspectives. Journal of Sport Management, 6 (2), pp. 114-132

SLS (2016) About the SLS. Available: http://streetleague.com/about/

Skinner, J., Stewart, B. and Edwards, A. (1999) Amateurism to Professionalism: Modelling Organisational Change in Sporting Organisations. Sport Management Review (Sport Management Association of Australia \& New Zealand), 2 (2), pp. 173-192.

Skirstad, B. and Chelladurai, P. (2011) For 'Love' and Money: A Sports Club's Innovative Response to Multiple Logics. Journal of Sport Management, 25 (4), pp. 339-353.

Smith, A.C.T. and Shilbury, D. (2004) Mapping Cultural Dimensions in Australian Sporting Organisations. Sport Management Review, 7 (2), pp. 133-165.

Southall, R. M. and Nagel, M. S. (2008). A case-study analysis of NCAA Division I women's basketball tournament broadcasts: Educational or commercial activity? International Journal of Sport Communication, 1(4), 516-533

Southall R.M., Nagel M.S., Amis J.M. and Southall C. (2008) A method to march madness? institutional logics and the 2006 National Collegiate Athletic Association Division I men's basketball tournament. Journal of Sport Management, 22 (6), pp. 677-700.

Stemler, S. (2001) An overview of content analysis. Practical Assessment, Research \& Evaluation, 7(17).

Stratford, B. (no date) Gary Ream Doesn't Speak For Me: Why I cannot and will never support skateboarding in the Olympics. Available: http://realskate.com/MrReam.pdf. 
Steen-Johnsen, K. (2008) Networks and the Organisation of Identity: The Case of Norwegian Snowboarding. European Sport Management Quarterly, 8 (4), pp. 337-358

Suchman, M. C. (1995) "Managing Legitimacy: Strategic and Institutional Approaches", Academy of Management Journal, Vol. 20, No. 3, pp. $571-610$

TSC (2016) Tokyo 2020 Skateboarding Commission Available http://skateboarding2020.com/

Thorpe, H. and Wheaton, B. (2011) 'Generation X Games', Action Sports and the Olympic Movement: Understanding the Cultural Politics of Incorporation. Sociology, 45 (5), pp. 830-847.

Tomlinson, A., Ravenscroft, N., Wheaton, B. and Gilchrist, P. (2005) Lifestyle Sports and National Sport Policy: An Agenda for Research [Report (for external body)]

WCS (2016) World Cup Skateboarding History Available: http://www.wcsk8.com/history-of-wcS

WSF (2016) World Skateboarding Federation: About Available: http://worldskateboardingfederation.org/about/

Wheaton, B. (2004) Understanding lifestyle sports: consumption, identity and difference. London: Routledge.

X-Games (2014) Would you rather see skateboarding in the Olympics or hoverboards come to life? Facebook post with comments. Available: https://www.facebook.com/XGames/posts/10152005468606964.

Yin, R.K. (2009) Case study research: design and methods. Los Angeles. Cal.: Sage

Young, N. (2013) ICON: Don Bostick. Topgrom, Summer, 19 April, 2014, p.38-41. Available: http://issuu.com/sbittle/docs/topgrom-mag-22-issuu-190dpi?e=8384272/4355435.

Zucker, L.G. (1977) The Role of Institutionalization in Cultural Persistence. American Sociological Review, 42 (5), pp. 726743. 
Appendix one: List of interviewees

1. Christian Baumann, Switzerland, Deputy Director and the IOC Liaison of the International Cycling Union (2007 2014);

2. Neil Danns, UK, one of the first professional skateboarders in Europe, British and European Champion;

3. Ryan Decenzo, Canada, professional skateboarding athlete;

4. Sandro Dias, Brazil, professional skateboarding athlete;

5. Rob Dyrdek, USA, former professional skateboarding athlete, founder of the Street League Skateboarding (since 2010);

6. Cecilia Flatum, Norway, Vice-President of the World Snowboarding Federation (since 2012), Board Member of Norwegian Snowboard Federation (2003-2015);

7. Gerhard Heiberg, Norway, the Member of the IOC Executive Board (2003-2011); Chair of the IOC Marketing Commission (2001-2014);

8. Neal Hendrix, USA, professional skateboarding athlete, Athlete Representative and the Chair of the International Events Committee at the International Skateboarding Federation (since 2010), Athlete Representative at Tokyo 2020 Skateboarding Commission (since 2016);

9. Christophe Hubschmid, Switzerland, Director General of the International Cycling Union (2011 - 2013);

10. Brad McClain, USA, professional skateboarding athlete;

11. Gary Ream, USA, the President of the International Skateboarding Federation (since 2004), President and partner in Sports Management Group, Inc., owner of Woodward Camp;

12. Elliot Sloan, USA, professional skateboarding athlete. 